2. Selleng K, Warkentin TE, Greinacher A. Heparin-induced thrombocytopenia in intensive care patients. Crit Care Med 2007;35:1165-76.

3. Zwicker JI, Uhl L, Huang WY, Shaz BH, Bauer KA. Thrombosis and ELISA optical density values in hospitalized patients with heparin-induced thrombocytopenia. J Thromb Haemost 2004;2:2133-7.

4. Pouplard C, Gueret P, Fouassier M, Ternisien C, Trossaert M, Régina S, et al. Prospective evaluation of the '4Ts' score and particle gel immunoassay specific to
heparin/PF4 for the diagnosis of heparin-induced thrombocytopenia. $J$ Thromb Haemost 2007;5:1373-9.

5. Eichler P, Budde U, Haas S, Kroll H, Loreth RM, Meyer O, et al. First workshop for detection of heparin-induced antibodies: validation of the heparin-induced plateletactivation test (HIPA) in comparison with a PF4/heparin ELISA. Thromb Haemost 1999;81:625-9.

\title{
A potential of autologous pericardium for a sustained-release carrier of vancomycin: A pilot study in vitro
}

\author{
Akira Marui, MD, PhD, ${ }^{\text {a }}$ Keiichi Hirose, MD, PhD, ${ }^{\text {a }}$ Hisashi Sakaguchi, MD, ${ }^{\text {a }}$ Yoshio Arai, MD, PhD, ${ }^{\text {a }}$ \\ Kazuhiko Doi, MD, PhD, ${ }^{\mathrm{b}}$ Masaki Tsukashita, MD, ${ }^{\mathrm{a}}$ Takeshi Shimamoto, MD, ${ }^{\mathrm{a}}$ Tadashi Ikeda, MD, PhD, ${ }^{\mathrm{a}}$ and \\ Masashi Komeda, MD, PhD, ${ }^{\text {a }}$ Kyoto, Japan
}

Autologous pericardium has been widely used to repair destructed annuli in infective endocarditis complicated by annular abscess. ${ }^{1,2}$ In the present study we investigated the in vitro property of autologous pericardium for a sustainedrelease carrier of vancomycin.

\section{CLINICAL SUMMARY}

Between January and May 2002, autologous pericardium with pericardial fat was harvested from the patients $(n=6)$ who underwent cardiac operations in our institute. After harvesting, the pericardium was cut into 7 pieces $(1 \mathrm{~cm} \times 1 \mathrm{~cm}$ each). Then $0.2 \mathrm{~mL}$ of vancomycin solution $(15 \mathrm{mg} / \mathrm{mL})$ was dropped onto each pericardium and incubated for 1 hour at room temperature so that the vancomycin solution was completely absorbed into the pericardium. The 7 pericardial patches with vancomycin were soaked in 7 test tubes containing $5 \mathrm{~mL}$ of saline, respectively. The test tubes were placed in the shaker and kept at $37^{\circ} \mathrm{C}$. At 6 hours, 12 hours, and $1,3,5,7$, and 10 days after the incubation, the pericardium and the saline samples were collected and frozen from 1 of the 7 test tubes, and the saline in the residual test tubes were replaced with $5 \mathrm{~mL}$ of fresh saline (ie, the pericardia were left uncollected), respectively. We replaced the saline in the residual test tubes at each time point to maintain the

\footnotetext{
From the Department of Cardiovascular Surgery, ${ }^{\text {a }}$ Kyoto University Graduate School of Medicine and the Department of Cardiovascular Surgery, ${ }^{\mathrm{b}}$ Takeda Hospital, Kyoto, Japan.

Received for publication Dec 9, 2007; revisions received Jan 18, 2008; accepted for publication Feb 4, 2008.

Address for reprints: Masashi Komeda, MD, PhD, Department of Cardiovascular Surgery, Kyoto University Graduate School of Medicine, 54 Shogoin-Kawahara, Sakyo, Kyoto, 606-8507 Japan (E-mail: komelab@kuhp.kyoto-u.ac.jp).

J Thorac Cardiovasc Surg 2009;137:783-4

$0022-5223 / \$ 36.00$

Copyright (C) 2009 by The American Association for Thoracic Surgery

doi:10.1016/j.jtcvs.2008.02.041
}

diffusion gradient between the pericardium and the saline. To prevent the degradation of the samples, we froze them until the concentrations of vancomycin were measured. The vancomycin concentrations of the pericardium and the saline samples were measured as previously described. ${ }^{3,4}$ We obtained written informed consent from each patient after a full explanation of this study. The protocol of this study complied with the principles set forth in the Helsinki Declaration.

All values are expressed as means \pm standard deviations. Figure 1 shows that the percentage reaming of vancomycin in the pericardium at each time point was $67.8 \% \pm 17.8 \%$, $53.8 \% \pm 12.3 \%, 37.8 \% \pm 9.8 \%, 25.1 \% \pm 10.1 \%, 12.6 \%$ $\pm 3.3 \%, 7.1 \% \pm 3.1 \%$, and $4.3 \% \pm 1.7 \%$ for 6 hours, 12 hours, and 1, 3, 5, 7, and 10 days after the incubation, respectively. Figure 2 shows that the concentrations of vancomycin in the saline samples were $789 \pm 143 \mu \mathrm{g} / \mathrm{mL}$, $376 \pm 56 \mu \mathrm{g} / \mathrm{mL}, 144 \pm 23 \mu \mathrm{g} / \mathrm{mL}, 56 \pm 14 \mu \mathrm{g} / \mathrm{mL}, 38 \pm$ $5.2 \mu \mathrm{g} / \mathrm{mL}, 27 \pm 3.8 \mu \mathrm{g} / \mathrm{mL}$, and $15 \pm 2.7 \mu \mathrm{g} / \mathrm{mL}$ for 6 hours, 12 hours, and 1, 3, 5, 7, and 10 days after the incubation, which were all greater than the minimum inhibitory concentration of vancomycin $(2.0 \mu \mathrm{g} / \mathrm{mL})$ against methicillin-resistant Staphylococcus aureus (MRSA). These results indicate that the pericardium can slowly release vancomycin and maintain the minimum inhibitory concentration of MRSA around the pericardium for more than 10 days.

\section{DISCUSSION}

In the present study we found that the autologous pericardium with fat might have a potential for a sustained-release carrier of vancomycin. Although this is an in vitro study and the mechanism of the sustained release was unclear, the property might help prevent prosthetic valve endocarditis by MRSA after reconstruction of the infected annulus.

Antibiotics are usually administrated systematically to prevent all forms of infection; however, this might be 


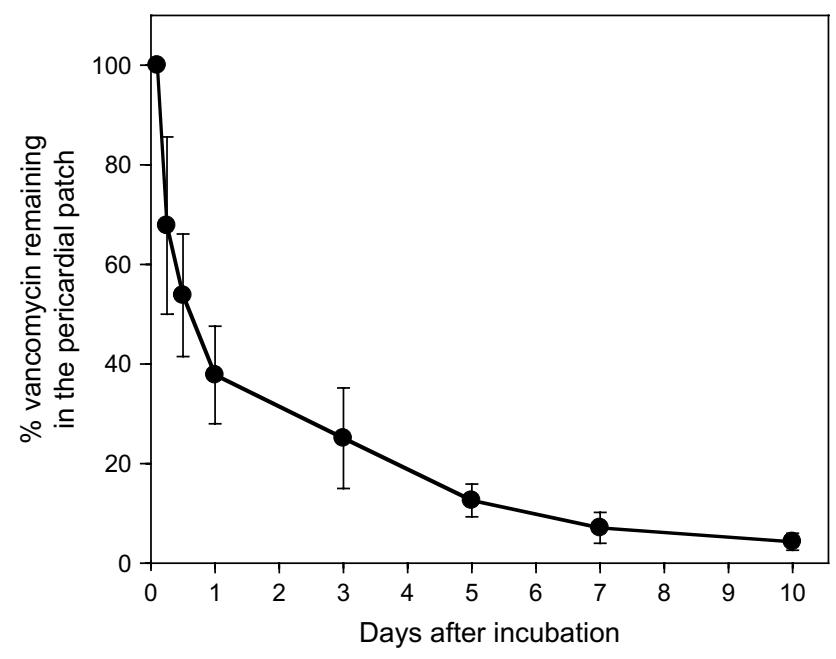

FIGURE 1. Release profile of vancomycin from the pericardium.

insufficient to treat prosthetic valve endocarditis because the prosthesis directly contacts the infective sites. ${ }^{1,2}$ Furthermore, maintenance of a sufficient blood concentration of antibiotics is sometimes difficult because prolonged systemic administration of high-dose antibiotics induces serious organ damage.

To avoid such disadvantages, we developed a local sustained-release system of vancomycin by using a poly-L-lactide-co-caprolactone sheet. ${ }^{3,4}$ This sustained-release sheet of vancomycin drastically reduced the number of MRSA cells and prevented graft infection of the subcutis ${ }^{3}$ and the abdominal aorta. ${ }^{4}$ However, the fragile poly-L-lactide-cocaprolactone sheet cannot tolerate surgical manipulation and might cause thromboembolism if used in the cardiac cavity. On the other hand, autologous pericardium can be applied in several situations of cardiothoracic surgery, including annular reconstruction, and can be advantageous in terms of biocompatibility. However, it is difficult to know from the present data whether the same pericardial concentrations are maintained under more physiologic conditions. Thus further studies by large animals are required to determine the efficacy in vivo.

Fibrin glue has been applied as a carrier for vancomycin ${ }^{5}$; however, it can also cause serious thromboembolism. In

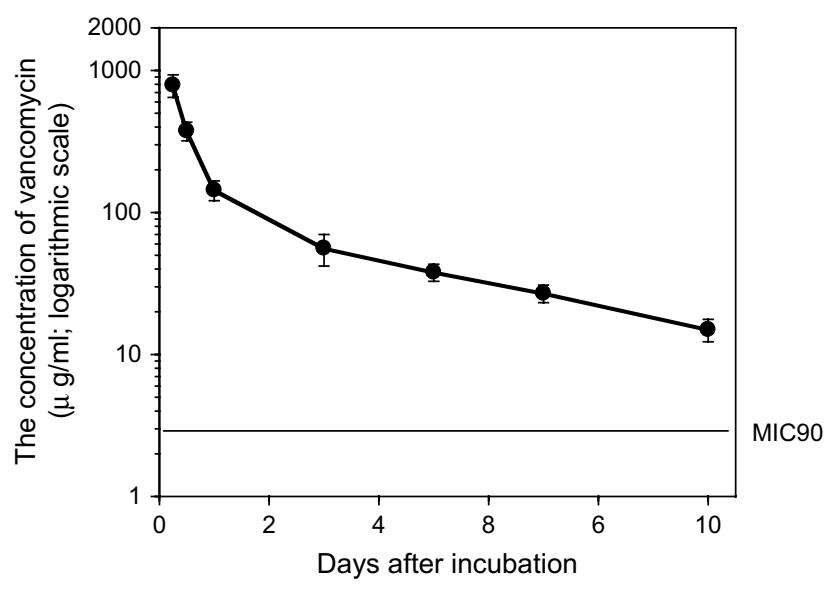

FIGURE 2. Concentration of vancomycin in the saline samples. MIC, Minimum inhibitory concentration.

addition, fibrin glue cannot release antibiotics for a sufficient period and the property of sustained release of vancomycin from the fibrin glue was not satisfactory compared with those of other antibiotics, such as teicoplanin and gentamicin. ${ }^{5}$ We did not use glutaraldehyde for the preparation of pericardium to maintain its antibacterial and sustainedrelease properties.

In conclusion, autologous pericardium might have a potential for a sustained-release carrier of vancomycin. Further studies are required to determine the efficacy in vivo.

\section{References}

1. David TE, Gavra G, Feindel CM, Regesta T, Armstrong S, Maganti MD. Surgical treatment of active infective endocarditis: a continued challenge. J Thorac Cardiovasc Surg 2007; 133:144-9.

2. Knosalla C, Weng Y, Yankah AC, Siniawski H, Hofmeister J, Hammerschmidt R, et al. Surgical treatment of active infective aortic valve endocarditis with associated periannular abscess_-11 year results. Eur Heart J 2000;21:490-7.

3. Hirose K, Marui A, Arai Y, Nomura T, Inoue S, Kaneda K, et al. Sustained-release vancomycin sheet may help to prevent prosthetic graft methicillin-resistant Staphylococcus aureus infection. J Vasc Surg 2006;44:377-82.

4. Sakaguchi H, Marui A, Hirose K, Nomura T, Arai Y, Bir SC, et al. Less invasive and highly effective method for preventing methicillin-resistant Staphylococcus aureus graft infection by local sustained release of vancomycin. J Thorac Cardiovasc Surg 2008;135:25-31.

5. Marone $\mathrm{P}$, Monzillo V, Segù C, Antoniazzi E. Antibiotic-impregnated fibrin glue in ocular surgery: in vitro antibacterial activity. Ophthalmologica 1999;213:12-5. 